\title{
Prevalence of BTK mutations in male Algerian patterns with agammaglobulinemia and severe B cell lymphopenia zrs $^{2}$
}

\author{
Soraya Boushaki a,b ${ }^{\text {, Azzedine Tahiat }}{ }^{\mathrm{a}, 1}$, Yanis Meddour ${ }^{\mathrm{c}, 1}$, Koon Wing Chan ${ }^{\mathrm{d}}$, Samia Chaib ${ }^{\mathrm{c}}$, Nafissa Benhalla ${ }^{\mathrm{e}}$, \\ Leila Smati ${ }^{\mathrm{f}}$, Abdellatif Bensenouci ${ }^{\mathrm{g}}$, Yu-Lung Lau ${ }^{\mathrm{d}}$, Frédérique Magdinier ${ }^{\mathrm{h}}$, Réda Djidjik ${ }^{\mathrm{a}, \mathrm{i}, *}$ \\ a Immunology Department, Beni Messous Teaching Hospital, Algiers, Algeria \\ b Unit of Genetics, Laboratory of Molecular and Cellular Biology, Faculty of Biological Sciences, University of Sciences and Technology "HouariBoumediene" Algiers, Algeria \\ ' Immunology Department, Central Hospital of the Army, Algiers, Algeria \\ d Department of Pediatrics and Adolescent Medicine, The University of Hong Kong, Pokfulam, Hong Kong \\ e Pediatrics Department A, Beni Messous Teaching Hospital, Algiers, Algeria \\ ${ }^{\mathrm{f}}$ Pediatrics Department, Bologhine Hospital, Algiers, Algeria \\ g Pediatrics Department B, Beni Messous Teaching Hospital, Algiers, Algeria \\ ${ }^{\mathrm{h}}$ Laboratoire de Génétique Médicale et Génomique Fonctionnelle, INSERM UMR S-910, Aix Marseille Université, Faculté de Médecine de la Timone, Marseille, France \\ ${ }^{i}$ Laboratory of Immunology, Faculty of Medicine, University of Algiers 1, Algeria
}

\section{A R T I C L E I N F O}

\section{Article history:}

Received 28 August 2015

Received in revised form 15 September 2015

accepted with revision 16 September 2015

Available online 24 September 2015

\section{Keywords:}

$\mathrm{X}$ linked agammaglobulinemia

XLA

BTK mutations

Algeria

\begin{abstract}
A B S T R A C T
$\mathrm{X}$ linked agammaglobulinemia (XLA) is the first described primary immunodeficiency and the most common form of agammaglobulinemia. It is characterized by susceptibility to recurrent infections, profound decrease of all immunoglobulin isotypes and very low level of B lymphocytes in peripheral blood. The disorder is caused by mutations in the Bruton's Tyrosine Kinase (BTK). Nine male patients suspected to have XLA from nine unrelated families were enrolled in this study. We performed sequencing of the BTK gene in all nine patients, and in the patients' relatives when possible. The XLA diagnosis was confirmed for six patients with six different mutations; we identified a novel mutation (c.1522G $>$ A) and five known mutations. One third of nine unrelated patients do not have mutations in BTK and thus likely suffer from autosomal recessive agammaglobulinemia in the setting of consanguinity. Our results support that the autosomal recessive agammaglobulinemia can be more common in Algeria.
\end{abstract}

\section{Introduction}

The prototypical humoral immunodeficiency, the X-linked agammaglobulinemia (XLA; MIM\#300300), was first described by Ogden C. Bruton in 1952 [1]. It is a fully penetrant X-linked recessive disorder and occurs in approximately one in 200,000 individuals [1,2]. It is characterized by an increased susceptibility to bacterial infections, severe reduction in all serum immunoglobulin isotypes and a profound decrease or absence of peripheral blood B lymphocytes [3]. It is caused by mutations of the Bruton's tyrosine kinase (BTK) gene resulting in profound

\footnotetext{
th None of the authors has any potential financial conflict of interest related to this manuscript.

* Corresponding author at: Immunology Department, Beni Messous Teaching Hospital, Rue BrahimHadjeres, 16000 Algiers, Algeria.

E-mail address: ourtilane@yahoo.fr (R. Djidjik).

1 Equal contributors.
}

block of B cell differentiation at early stages in the bone marrow. The BTK gene containing 19 exons is localized at the Xq21.3-Xq22 locus, encompasses $37.5 \mathrm{~kb}$ and codes for a 659 amino-acid protein which plays a crucial role in B cell development and function. BTK consists of five structural domains: a Pleckstrin Homology (PH) domain, a Tec Homology (TH) domain, an Src Homology 3 (SH3) domain, an SH2 domain and an SH1 domain (catalytic kinase domain) [2,4]. Mutations in patients with XLA are spread throughout the BTK gene in coding and non-coding regions. Many of the reported mutations are gathered in the international BTKbase [http://bioinf.uta.fi/BTKbase/]. Most of them are missense mutations in all domains except SH3, possibly because the stability of this domain is refractory to missense mutations, but also deletions, splice-site mutations and insertions. The frequency of mutations depends on the length of the domain [5].

In Algeria, the prevalence of XLA is still unknown. XLA diagnosis is based only on clinical manifestations such as recurrent infections, hypogammaglobulinemia and decreased circulating B cells which are 
insufficient to establish a correct diagnosis. In this study, we describe nine unrelated Algerian male patients clinically diagnosed with XLA. Using genetic analysis we confirm the presence of mutation in the BTK gene and XLA diagnosis in six of them.

\section{Materials and methods}

\subsection{Patients}

We report nine unrelated male patients with agammaglobulinemia native from different areas of Algeria. Patients were referred by physicians to our laboratory during the 2010-2014 period. Patients' epidemiological and clinical information were collected. Agammaglobulinemia suspicion was based on increased susceptibility to bacterial infections, severe reduction in all serum immunoglobulin isotypes and significant decreased or absence of peripheral blood B lymphocytes (according to the diagnostic criteria for agammaglobulinemia from the International Union of Immunological Societies Expert Committee for Primary Immunodeficiency) [3]. The rate of consanguinity reaches $66 \%$. The patients AGM1, 3, 6, 7, 8 and 9 are from related parents. AGM3, 7 and 8 parents' are first cousin, AGM3 and AGM8 had a familial history of recurrent infections. Clinical features are presented in Table 1. Consent of participation in this study was obtained from the patients or their parents. Blood samples from the patient's, and when possible their family members, were collected on EDTA and processed in our laboratory.

\subsection{Immunological analysis}

Serum immunoglobulin concentration was determined by nephelometry, using the BN ProSpec ${ }^{\mathrm{TM}}$ System (Siemens). Peripheral blood leucocytes immunophenotyping was carried out by flow cytometry with a BD FACS Canto ${ }^{\mathrm{TM}}$, using a panel of monoclonal antibodies directed against CD45, CD3, CD4, CD8, CD19 and CD20, labeled with either fluorescein (FITC), phycoerythrin (PE), PerCP or PerCP-Cy 5.5 or PECy ${ }^{\mathrm{TM}} 7$ or APC (Becton Dickinson).

\subsection{Mutation detection in the BTK gene}

Genomic DNA was isolated from patients, family members and control healthy individuals using a conventional Salting Out method [6].All $B T K$ gene exons and the intron-exon junctions were amplified by PCR using a set of primers described by Yu et al. [20]. In brief, 50 ng of gDNA was amplified in $50 \mu \mathrm{l}$ containing: $4 \mu \mathrm{M}$ of each primer, $10 \mu \mathrm{M}$ of dNTP mix, $5 \mu \mathrm{l}$ of buffer, and $0.4 \mu \mathrm{l}$ of Taq DNA Polymerase. The following program was used for all exons amplifications: pre-heating at $94{ }^{\circ} \mathrm{C}$ during $5 \mathrm{~min}$ and then 35 cycles at $94{ }^{\circ} \mathrm{C}$ for $1 \mathrm{~min}, 60{ }^{\circ} \mathrm{C}$ for
$1 \mathrm{~min}$ and $72{ }^{\circ} \mathrm{C}$ for $1 \mathrm{~min} 30 \mathrm{~s}$, with $5 \mathrm{~min}$ final extension at $72{ }^{\circ} \mathrm{C}$. The PCR fragments were sent for sequencing (Eurofins). Results were analyzed and aligned using the UGEN and BioEdit softwares to detect mutations in the coding sequences and exon/intron junctions. The annotations and numbering of amino acids and nucleotides were done referring to the BTK gene sequenceENST00000308731 (NM_000061 and NP_000052).

\section{Results}

\subsection{Clinical features}

Nine male patients with agammaglobulinemia or severe hypogammaglobulinemia from nine unrelated families were enrolled in this study. The median age of onset of agammaglobulinemia symptoms was 15 months (range: 3 months- 4 years) and the median age of diagnosis was 6.7 years (range: 9 months-26 years). All the nine patients presented with respiratory infections, and the majority of them have bronchiectasis (77\%). Otitis media (2/9), arthritis (1/9) and skin infection (1/9) are less present. Patients AGM1, AGM3, AGM6, AGM7, AGM8 and AGM9 exhibit inbreeding while patients AGM2, AGM4 and AGM5 are not from wedding consanguine (Table 1).

AGM3 had family history of early death because of recurrent infections in maternally related males (four uncles and a brother) (Fig. 1). AGM8 also had a family history of early death. His first sister presented with recurrent urinary infections and his second sister died of septicemia at the age of 2 .

\subsection{Immunoglobulins and circulating $B$ cells percentages}

Patients did not receive intravenous immunoglobulin (IVIG) substitution therapy before the XLA diagnosis. The nine patients had very low levels of serum immunoglobulins (Table 2) which is characteristic of XLA. The concentrations were: less than $300 \mathrm{mg} / \mathrm{dl}$ for IgG, less than $25 \mathrm{mg} / \mathrm{dl}$ for IgA and less than $40 \mathrm{mg} / \mathrm{dl}$ for IgM immunoglobulins. Peripheral blood leucocytes immunophenotyping showed $0 \%$ circulating B Lymphocytes (Table 2).

\subsection{A novel mutation and five reported mutations}

Nine male patients recruited in this study were analyzed at the genetic level by BTK gene sequencing.AGM1 carries a de novo mutation (c.1522G $>A$ ) in exon 15 corresponding to the SH1 domain of the BTK protein (Table 3) which has never been reported in the past. AGM2, AGM3, AGM5and AGM6 carry mutations previously reported, c.1952T $>$ G, c.1922G $>$ A, c.552-557insA and c.1574G $>$ A respectively

Table 1

Clinical features of XLA suspected patients.

\begin{tabular}{|c|c|c|c|c|c|c|c|c|c|}
\hline Patient & $\begin{array}{l}\text { Age at } \\
\text { onset }\end{array}$ & $\begin{array}{l}\text { Age at } \\
\text { diagnostic }\end{array}$ & Inbreeding & Family history & Pneumonia & Bronchiectasis & $\begin{array}{l}\text { Otitis } \\
\text { media }\end{array}$ & Arthritis & $\begin{array}{l}\text { Skin } \\
\text { infection }\end{array}$ \\
\hline AGM1 & $\begin{array}{l}3 \\
\text { months }\end{array}$ & 9 months & + & - & + & + & - & - & - \\
\hline AGM2 & & 26 years & - & - & + & + & - & - & - \\
\hline AGM3 & $\begin{array}{l}12 \\
\text { months }\end{array}$ & 3 years & $+\left(2^{\circ}\right)$ & $\begin{array}{l}+ \text { (a brother and } 4 \text { maternal uncles died after recurrent } \\
\text { infections) }\end{array}$ & + & + & - & - & + \\
\hline AGM4 & & 8 years & - & - & + & + & - & - & - \\
\hline AGM5 & $\begin{array}{l}48 \\
\text { months }\end{array}$ & 7 years & - & - & + & + & + & - & - \\
\hline AGM6 & $\begin{array}{l}24 \\
\text { months }\end{array}$ & 5 years & + & - & + & + & - & - & - \\
\hline AGM7 & $\begin{array}{l}3 \\
\text { months }\end{array}$ & 7 years & $+\left(2^{\circ}\right)$ & - & + & + & - & + & - \\
\hline AGM8 & $\begin{array}{l}12 \\
\text { months }\end{array}$ & 3 years & $+\left(2^{\circ}\right)$ & $\begin{array}{l}+ \text { (sister } 1 \text { died at } 2 \text { years after septicemia, sister } 2 \text { presents } \\
\text { recurrent urinary infection) }\end{array}$ & + & - & - & - & - \\
\hline AGM9 & $\begin{array}{l}6 \\
\text { months }\end{array}$ & 9 months & + & - & + & - & + & - & - \\
\hline
\end{tabular}




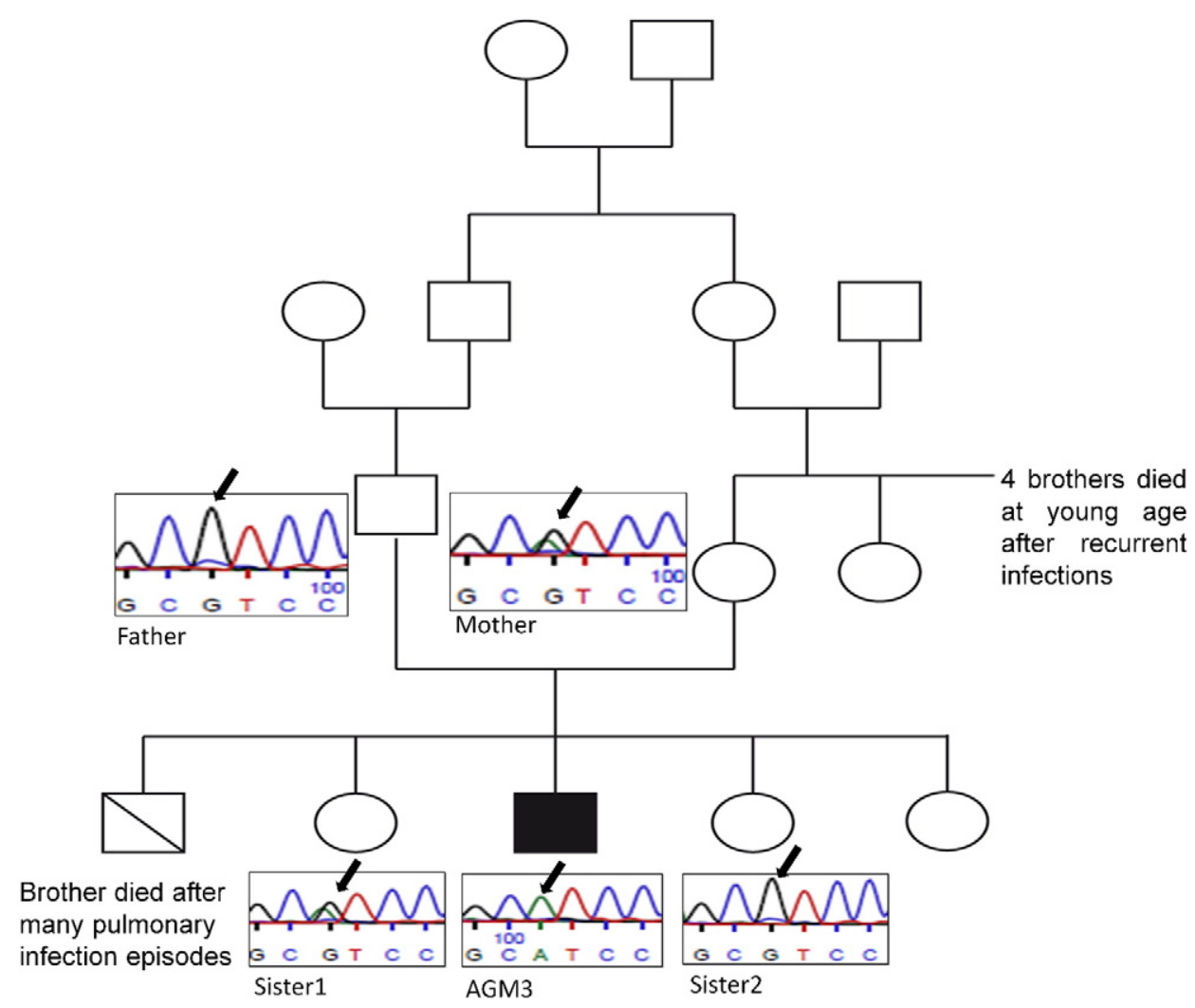

Fig. 1. Information related to patient AGM3: patient's family pedigree and direct sequencing of genomic DNA of patient and his family members.

(Table 3). AGM4 carries a deletion of exon 6 and 7 (g. Ex6_Ex7 del), a mutation which has also been reported. The mother and one sister of AGM3 carry the same mutation (c.1922G>A; Fig. 1). The AGM5 mother is a carrier of the mutation reported in her son (552-557insA). The sequencing of the BTK gene did not reveal any mutation in the AGM7, AGM8 and AGM9 patients.

\section{Discussion}

XLA is the most common form of agammaglobulinemia. It is characterized by recurrent bacterial infections, profound decrease in immunoglobulins and B lymphocytes in peripheral blood. It is caused by defects in the BTK gene. More than 1100 mutations involving all BTK domains were described $[2,5]$. In this study we present nine male patients, from nine unrelated families, who clinically and immunologically have a diagnosis compatible with XLA. We confirmed XLA diagnosis by sequencing of BTK gene in six of them.

It should be noted that all patients with no exonic BTK mutations are from consanguineous parents and one of the three, patient AGM8, has a positive family history involving female siblings with recurrent infections. Overall, these suggest an autosomal recessive agammaglobulinemia. Because of the high rate of consanguinity in Algeria, autosomal recessive agammaglobulinemia can be more common than reported in Western countries. It was already noted that autosomal recessive primary immunodeficiencies are more common in areas with a high rate of consanguinity [7].

The median age of onset of symptoms in the six patients with confirmed XLA patients was 21.75 months (range: 3 months- 4 years) and the median age of diagnosis of these patients was 8.3 years (range: 9 months-26 years).No patients with positive family history were screened for XLA before onset of infections. This delay in diagnosis is longer than in other studies [2,8,9,and 10] due to lack of resources and knowledge of this disease in Algeria.

The clinical manifestations of the six Algerian patients with confirmed XLA diagnosis were typical and similar to other reports $[2,8$, and 11]: recurrent infections, panhypogammaglobulinemia and reduced levels of B lymphocytes in peripheral blood. One patient had family history of early death from recurrent infections. At diagnosis all patients had recurrent pneumonias and had developed bronchiectasis due to delay of diagnosis hence of IVIG substitution therapy. One patient had otitis media and one patient had skin infections. Patient 3 had visceral leishmaniasis. Patient 6 had severe otitis, chronic diarrhea and

Table 2

Immunological features of XLA suspected patients.

\begin{tabular}{|c|c|c|c|c|c|c|c|c|c|}
\hline Patient & $\operatorname{IgG}(\mathrm{mg} / \mathrm{dl})$ & $\operatorname{IgA}(\mathrm{mg} / \mathrm{dl})$ & $\operatorname{IgM}(\mathrm{mg} / \mathrm{dl})$ & CD19 (\%) & CD3 (\%) & CD4 (\%) & CD8 (\%) & $\mathrm{CD} 4 / \mathrm{CD} 8$ & Neutropenia \\
\hline AGM1 & 24.4 & $<2.1$ & 22.4 & 0 & 97.5 & 72 & 23 & 3.13 & + \\
\hline AGM2 & 20.5 & / & / & 0 & 90 & 27 & 46 & 0.58 & - \\
\hline AGM3 & $<33.3$ & $<6.7$ & 12.9 & 0 & 94 & 47 & 45 & 1.04 & + \\
\hline AGM4 & 121 & $<24.4$ & $<17.5$ & 0 & 75 & 38 & 26 & 1.46 & - \\
\hline AGM5 & 89.9 & $<2.1$ & $<10.1$ & 0 & 98 & 26 & 69 & 0.38 & - \\
\hline AGM6 & $<17.6$ & / & $<34.3$ & 0 & 88 & 46 & 38 & 1.21 & - \\
\hline AGM7 & 257 & $<6.67$ & 16.2 & 0 & 83 & 43 & 52 & 0.8 & - \\
\hline AGM8 & $<7.23$ & $<24.4$ & $<17.5$ & 0 & 90 & 29 & 54 & 0.5 & - \\
\hline AGM9 & 140 & $<6$ & 37 & 0 & 91 & 58 & 33 & 1.7 & - \\
\hline
\end{tabular}


Table 3

Mutational features of XLA patients.

\begin{tabular}{|c|c|c|c|c|c|}
\hline Patient & Exon & $\begin{array}{l}\text { Nucleotide } \\
\text { change }\end{array}$ & $\begin{array}{l}\text { Protein } \\
\text { domain }\end{array}$ & $\begin{array}{l}\text { Predicted change in } \\
\text { codon }\end{array}$ & $\begin{array}{l}\text { Mother } \\
\text { status }\end{array}$ \\
\hline AGM1 & 15 & c. $1522 \mathrm{G}>\mathrm{A}$ & SH1 & A508T & $\begin{array}{l}\text { Non } \\
\text { carrier }\end{array}$ \\
\hline AGM2 & 19 & c. $1952 \mathrm{~T}>\mathrm{G}$ & SH1 & I651S & Not done \\
\hline AGM3 & 19 & c. $1922 \mathrm{G}>\mathrm{A}$ & SH1 & $\mathrm{R} 641 \mathrm{H}$ & carrier \\
\hline AGM4 & $\begin{array}{l}6 \text { and } \\
7\end{array}$ & g. Ex6_Ex7 del & PH, TH & l & Not done \\
\hline AGM5 & 7 & c.552-557insA & $\mathrm{TH}$ & Lys186fsX8 & Carrier \\
\hline AGM6 & 16 & c. $1574 G>A$ & SH1 & R525Q & / \\
\hline AGM7 & / & ND & / & / & / \\
\hline AGM8 & / & ND & / & / & / \\
\hline AGM9 & I & ND & / & l & / \\
\hline
\end{tabular}

oral candidiasis. Patients 2 and 5 had an inversion of $C D 4 / C D 8$ ratio, the same observation was made by $\mathrm{Vu}$ et al. in Vietnamese XLA patients with arthritis [12]but our patients did not have arthritis. Arthritis is frequent in Chinese XLA patients (29\%) but less frequent in Caucasian patients (7-16\%) [13].

We detected six different mutations in the BTK gene in six patients. Four of these mutations are in the SH1 domain, one mutation is in the $\mathrm{TH}$ domain and one alters the $\mathrm{TH}$ and $\mathrm{PH}$ domains. This distribution of mutations is similar with the distribution of mutations in the BTK database ( $44.7 \%$ on the SH1 domain, $21.8 \%$ on the PH domain, $13.7 \%$ on the $\mathrm{SH} 2$ domain, $8.3 \%$ on the $\mathrm{TH}$ domain and $7 \%$ on the $\mathrm{SH} 3$ domain) which is proportional to the length of domains [5].

Four of the six mutations are amino-acid substitutions, one mutation is a base pair insertion and one mutation is a large deletion involving two exons. This is in accordance with mutations described in the BTK database where the majority of mutations are single base pair substitutions which can occur in all domains except in the $\mathrm{SH} 3$ domain probably due to its stability. Approximately $20 \%$ of them are small insertions or deletions ( $1-5$ base pairs) and 5-10\% of them are large alterations (deletions and less frequently duplications, inversions and insertions) $[4,5]$.

Patient 1 had a missense mutation (c.1522G $>$ A) which resulted in an amino-acid substitution (alanine to threonine) at codon 508 at SH1 domain. It is a novel mutation not reported in the BTK database. The patient's mother and sister do not carry the mutation $(\mathrm{G} / \mathrm{G})$ indicating that they are not carriers. This nucleotide change is frequent $(23 \%)$ in the BTK base [14]. Saha et al. reported a patient with a mutation in the same codon and predicted structural consequences [15]. It is important to note that this mutation was absent in two healthy brothers of the patient and five healthy unrelated controls.

We do not had the exact age of onset of the symptoms for patient 2 but we know that the first signs occurred during his childhood. He carries a missense mutations (c.1952T $>\mathrm{G}$ ) leading to an isoleucine to serine substitution at codon 651 on the $\mathrm{SH} 1$ domain. This substitution is not very frequent in the BTK database (5\%) [14]. This mutation was described by Tóth et al. in a Hungarian patient [16].

Patient 3 had a missense mutation (c.1922G $>$ A) which resulted in an amino-acid substitution (arginine to histidine) at codon 641 at the $\mathrm{SH} 1$ domain. The patient's mother and a female sibling are heterozygous (G/A) and are carriers of the mutation (Fig. 1). This nucleotide substitution is frequent in the BTK database and this same mutation is described in many previous reports [4,14]. Speletas et al. described a Greek patient with the same mutation. The substitution replaces essentially invariant interaction of kinases. Ionic bond between E567 and R641 stabilizes the structure of the kinase [17].

Patient 4 carries a large deletion the boundaries of which we were not able to delineate. When the patient's genomic DNA was amplified there were no bands corresponding to the sizes of exons 6 and 7 suggesting that he carries the same deletion described by Tóth et al. in two Polish siblings with XLA (c.392 588del197bp) which leads to a truncation of the protein at the PH and TH domain (p.V131 Q196del) [16].
Patient 5 had a frame shift base-pair insertion (552-557insA) starting at K 186 and leading to a stop codon at position 193. The patient's mother is a carrier of the same mutation which was reported in previous studies [18,19].

Patient 6 had a missense mutation (c.1574G $>$ A) leading to an arginine to glutamine substitution at codon 525 at the SH1 domain. This mutation is described in many previous reports, Vihinen et al. confirmed that this mutation prevents the phosphorylation of the BTK protein [21].

Patients 1 and 3 had neutropenia at the time of diagnosis which was resolved after IVIG therapy. Neutropenia is described in 10-20\% of XLA patients. The reason underlying association between XLA and neutropenia is still unclear and there are no specific mutations associated with the occurrence of neutropenia [5].

Overall, there is no correlation between the genotype of patients and the clinical symptoms. Other factors can play an important role in the clinical features of the XLA patients besides the BTK mutations such as environmental variables, components of the BTK-dependent signaling pathway and variants in the innate immune system proteins [12,22].

\section{Conclusion}

Here we report for the first time the clinical and genetic diagnosis of XLA in Algerian patients. Nine patients were suspected to have XLA but only six of them were confirmed by genetic analysis suggesting that autosomal recessive agammaglobulinemia is more frequent in Algeria. Molecular genetic test is necessary for confirming XLA diagnosis. An early diagnosis can avoid clinical complications.

After DNA sequencing, we found six causative mutations in six unrelated families, one new mutation and five mutations previously reported in the BTK database.

The determination of patients' family members' status revealed in two cases that the mutations are transmitted by the mother and present in the sisters. Genetic counseling is needed for patients' families.

\section{Author's contribution}

SB designed, conducted, analyzed most of the experiments and wrote the manuscript.

YM and KWC conducted and analyzed sequencing experiments.

TA, CS provided patient's samples and carried out the immunoassays.

$\mathrm{NB}, \mathrm{DS}$ and $\mathrm{AB}$ provided clinical diagnosis of patients.

YLL and MF financed the molecular genetic studies and edited the manuscript.

DR designed the study, analyzed the data, supervised the project and edited the manuscript.

\section{Acknowledgment}

We would like to thank Prof Raif. S. Geha, for his collaboration.

We are also grateful to Dr. Tarik HAMADOUCHE and MrCherif BADJA for their participation to the analysis of the results. Finally we express our deepest gratitude to the patients and their families.

\section{References}

[1] O.C. Bruton, Agammaglobulinemia, Pediatrics 9 (1952) 722-728

[2] Z.-Y. Zhang, X.-D. Zhao, L.-P. Jiang, E.-M. Liu, M. Wang, J. Yu, P. Liu, X.-Q. Yang, Clinical characteristics and molecular analysis of 21 Chinese children with congenital agammaglobulinemia, Scand. J. Immunol. 72 (2010) 454-459.

[3] Al-Herz W, Bousfiha A, Casanova J-L, Chatila T, Conley ME, Cunningham-Rundles C, Etzioni A, Franco JL, Gaspar HB, Holland SM, Klein C, Nonoyama S, Ochs HD, Oksenhendler E, Picard C, Puck JM, Sullivan K and Tang MLK. Primary immunodeficiency diseases: an update on the classification from the International Union of Immunological Societies Expert Committee for Primary Immunodeficiency. Front. Immunol. 2014, 5:162

[4] M.E. Conley, J. Rohrer, Y. Minegishi, X-linked agammaglobulinemia, Clin Rev Aller Immu 19 (2000) 183-204. 
[5] G. López-Herrera, A. Vargas-Hernández, M.E. González-Serrano, L. Berrón-Ruiz, J.C. Rodríguez-Alba, F. Espinosa-Rosales, L. Santos-Argumedo, Bruton's tyrosine kinase-an integral protein of B cell development that also has an essential role in the innate immune system, J Leukoc Biol 95 (2014) 243-250.

[6] S.A. Miller, D.D. Dykes, H.F. Polesky, A simple salting out procedure for extracting DNA from human nucleated cells, Nucleic Acids Res. 16 (1988) 1215.

[7] W. Al-Herz, H. Aldhekri, N. BarboucheMRand Rezaei, Consanguinity and primary immunodeficiencies, Hum. Hered. 77 (2014) 138-143.

[8] A. Aghamohammadi, M. Fiorini, M. Moin, N. Parvaneh, S. Teimourian, M. Yeganeh, F. Goffi, H. Kanegane, A.A. Amirzargar, Z. Pourpak, N. Rezaei, A. Salavati, N. Pouladi, S. Abdollahzade, L.D. Notarangelo, A. MiyawakiTandPlebani, Clinical, immunological and molecular characteristics of 37 Iranian patients with X-linked agammaglobulinemia, Int. Arch. Allergy Immunol. 141 (2006) 408-414.

[9] M.E. Conley, V. Howard, Clinical findings leading to the diagnosis of X-linked agammaglobulinemia, J. Pediatr. 4 (2002) 566-571.

[10] A. Plebani, A. Soresina, R. Rondelli, G.M. Amato, C. Azzari, F. Cardinale, G. Cazzola, R. Consolini, D. De Mattia, G. Dell'Erba, M. Duse, M. Fiorini, S. Martino, B. Martire, M. Masi, V. Monafo, V. Moschese, L.D. Notarangelo, P. Orlandi, P. Panei, A.P.M.C. Pietrogrande, C. Pignata, I. Quinti, V. Ragno, P. Rossi, A. Sciotto, Stabile a and the Italian pediatric group for XLA-AIEOP: clinical, immunological, and molecular analysis in a large cohort of patients with X-linked agammaglobulinemia: an Italian multicenter study, Clin. Immunol. 104 (2002) 221-230.

[11] X. Qin, L.P. Jiang, X.M. Tang, M. Wang, E.M. Liu, X.D. Zhao, Clinical features and mutation analysis of X-linked agammaglobulinemia in 20 Chinese patients, World J. Pediatr. 9 (2013) 273-277.

[12] Q.V. Vu, T. Wada, H.T. Le, H.T. Le, A.T. Van Nguyen, O. Osamu, A. Yachie, S.N. Nguyen, Clinical and mutational features of Vietnamese children with X-linked agammaglobulinemia, BMC Pediatr 14 (2014) 129.

[13] P.P. Lee, T.X. Chen, L.P. Jiang, K.W. Chan, W. Yang, B.W. Lee, W.C. Chiang, X.Y. Chen, S.F. Fok, T.L. Lee, M.H. Ho, X.Q. Yang, Y.L. Lau, Clinical characteristics and genotypephenotype correlation in 62 patients with X-linked agammaglobulinemia, J ClinImmunol 30 (2010) 121-131.

[14] J. Valiaho, C.I. Smith, M. Vihinen, BTKbase: the mutation database for X-linked agammaglobulinemia, Hum. Mutat. 27 (2006) 1209-1217.
[15] B.K. Saha, S.K. Curtis, L.B. Vogler, M. Vihinen, Molecular and structural characterization of five novel mutations in the Bruton's tyrosine kinase gene from patients with X-linked agammaglobulinemia, Mol. Med. 3 (1997) 477-485.

[16] B. Tóth, A. Volokha, A. Mihas, M. Pac, E. Bernatowska, I. Kondratenko, A. Polyakov, M. Erdos, S. Pasic, M. Bataneant, A. Szaflarska, K. Mironska, D. Richter, K. Stavrik, T. Avcin, G. Márton, K. Nagy, B. Dérfalvi, M. Szolnoky, A. Kalmár, M. Belevtsev, M. Guseva, A. Rugina, G. Kriván, L. Timár, Z. Nyul, B. Mosdósi, L. Kareva, S. Peova, L Chernyshova, I. Gherghina, M. Serban, M.E. Conley, L.D. Notarangelo, C.I. Smith, J. van Dongen, M. van der Burg, L. Maródi, Genetic and demographic features of Xlinked agammaglobulinemia in Eastern and Central Europe: a cohort study, MolImmunol 46 (2009) 2140-2146.

[17] M. Speletas, M. Kanariou, F. Kanakoudi-Tsakalidou, E. Papadopoulou-Alataki, K. Arvanitidis, E. Pardali, A. Constantopoulos, G. Kaeralis, M. Vihinem, P. Sideras, K. Ritis, Analysis of Btk mutations in patients with X-linked agammaglobulinaemia (XLA) and determination of carrier status in normal female relatives: a nationwide study of Btk deficiency in Greece, Scand. J. Immunol. 54 (2001) 321-327.

[18] M.E. Conley, M.E. Fitch-Hilgenberg, J.L. Cleveland, O. Parolini, J. Rohrer, Screening of genomic DNA to identify mutations in the gene for Bruton's tyrosine kinase, HumMol Genet 3 (1994) 1751-1756.

[19] I. Vorechovský, L. Luo, J.M. Hertz, S.S. Frøland, T. Klemola, M. Fiorini, I. Quinti, R. Paganelli, H. Ozsahin, L. Hammarström, A.D. Webster, C.I. Smith, Mutation pattern in the Bruton's tyrosine kinase gene in 26 unrelated patients with X-linked agammaglobulinemia, Hum. Mutat. 9 (1997) 418-425.

[20] L. Yu, X. Wang, Y. Wang, J. Wang, Identification of two novel mutations in patients with X-linked primary immunodeficiencies, Fetal PediatrPathol 34 (2014) 91-98.

[21] M. Vihinen, D. Vetrie, H.S. Maniar, H.D. Ochs, Q. Zhu, I. Vorechovský, A.D. Webster L.D. Notarangelo, L. Nilsson, J.M. Sowadski, et al., Structural basis for chromosome X-linked agammaglobulinemia: a tyrosine kinase disease, Biochemistry 91 (1994) 12803-12807.

[22] A. Broides, Y. Wenjian, M.E. Conley, Genotype/phenotype correlations in X-linked agammaglobulinemia, Clin. Immunol. 118 (2006) 195-200. 